\title{
Influence of Kindergarten Curriculum on the Development of Creative Thinking Skills and Self-Efficacy among Kindergartners
}

\author{
Khalaf Ali Abbas Al-sagrat ${ }^{1, *} \&$ Ahmed Abd-ellatif Abu As'ad ${ }^{1}$ \\ ${ }^{1}$ Faculty of Educational Sciences, Mutah University, Jordan \\ *Corresponding author: Faculty of Educational Sciences, Mutah University, Jordan. E-mail: \\ ahmedased2009@yahoo.com
}

Received: November 9, 2014 Accepted: December 31, 2014 Published: January 30, 2015

doi:10.5296/ije.v7i1.7026 URL: http://dx.doi.org/10.5296/ije.v7i1.7026

\begin{abstract}
The current study aimed to identify the influence of kindergarten curriculum on the development of creative thinking skills and self-efficacy among kindergartners. The study was applied on a sample of (93) male and female kindergartners in Al-Karak governorate whom were randomly selected. Torrance test of creative thinking and the self-efficacy assessment scale (localized into Arabic version by the authors of this study) were applied. The two instruments were applied at the early attendance of children to kindergarten and application was replicated at the end of the academic year. Results indicated no significant statistical differences between the two groups in the development of creative thinking or self-efficacy that are attributed to the influence of public and private curriculum. For gender variable, it was indicated that there were no significant statistical differences in self-efficacy while these differences existed in creative thinking in favor of females.
\end{abstract}

Keywords: Kindergarten, Creative Thinking Skills, Self-Efficacy 


\section{Introduction}

Early childhood stage represents the most important stage in human life because of what distinguish this stage of flexibility, the ability for learning, growth of the various skills and abilities that shape their own world with all its experiences that lead to the development of the whole various aspects of growth including cognitive, emotional, and social development which in turn develops the child's ability of imagination, innovation, and infinite thinking.

In advanced and modern curriculums, child is regarded as the main axis in all activities of the curriculum as they always call child to self-activities and develop within him/her the element of experimentation, trying, and discovery in addition to encouraging him/her on free playing (Al-A'nani, 2002). Creative thinking among children is among the most important issues that attracts the concern of researchers for many decades regarding the methods of acquisition and development of creative thinking among them, in this context, Al-A'nani indicates three major reasons for concern in creative thinking: first, directing the concern within schools toward issues that contribute in student's thinking and developing his/her attitudes rather than merely focusing on conservation and memorization. Second, offering the student and the nation he/she belongs to a service that makes him/her familiar with authenticity, creativity, and innovation rather than being accustomed on dependence on others' efforts and thoughts. Third, preparing the student to future life as the creative individual is more adaptable with future and its needs and changes. Creative thinking is one of the most important types of thinking that Duffy (1998) illustrated in a number of points the most important among which is that creative thinking affords the individual an opportunity to develop his/her abilities and potentials to the maximum possible extent, proving his/her potentials to think and communicate, expressing all what he/she thinks, discovering values of things, understanding him/herself and others and comprehending their trust, and facing challenges and fulfilling the needs and requirements of rapid changes in the world.

In the other hand, Bandura (1991) indicates the necessity of increasing concern about developing self-efficacy among children which in turn concerns about the individual awareness for him/herself in addition to assessing his/her abilities to achieve a specific level of achievement and to control events, and judgment affect the level of self-efficacy in the nature of the goal the individual seeks to achieve and the exerted effort and the extent of the individual persistence in facing obstacles, his/her thinking approach. Self-efficacy determines wither the individual can realize the task he/she will engage in as representing an opportunity or a threat for him/her, and this affects the individuals' decision regarding to engage in the task or not, and also affects the behavior of initiation and persistence in the individuals' achievement situations.

Self-efficacy is also the personal belief regarding possessing compatible behavioral abilities that enable him/her to practically resolve a problem (Schwarzer,1994), and self-efficacy is regarded as one of the most important learning determinants that expresses a group of judgments that not only related to what individual achieves, but also to the judgment about what individual can achieve, and the self-efficacy theory is based on the individuals judgments about his/her ability to achieve or possessing specific behaviors (Bandura, 1991).

To be able to maintain creativity and to develop, a child must receive the necessary familial and 
school care, and school care is represented by the appropriate curriculum, the appropriate class environment that is rich with stimuli, and competence teachers to achieve self-efficacy. In this context, Murdan (2004) indicated a strong relationship between the nature of curriculums offered to the child within kindergarten and the regulation of these curriculums and the child's overall and comprehensive development in the various aspects. So, the researchers aimed to identify if there is an effect for the currently applied national interactive curriculum in Jordanian kindergartens on the development of kindergartners' creative thinking skills and teaching effectiveness among these children.

In the recent decade, intention toward the development of creative thinking skills among children has increased (Al-Srour, 2005). So, kindergarten institutions seek to design educational curriculums that assist children on developing their creative thin king and self-efficacy among them through giving the child a full freedom to practice activities and to discover his/her attitudes and abilities and hence they seek to assist the child to acquire new experiences and skills (Badran, 2000).

Kindergarten's curriculums in Jordan have received a great attention from the side of the ministry of education, this was mainly represented by drawing a comprehensive vision by the ministry of education for the most important teaching products that must be achieved among children in an attempt to place the child at the maximum stages of healthy development with its all dimensions. Kindergarten female teachers have received a reference and applied clear guide that serves the educational and teaching environment, along with what achieves the integration of benefit, knowledge, and excellence (Al-A'ssaf and Latifah, 2008).

The comprehensive interactive national curriculum was developed by a specialized national team which was supervised by the national committee for the development of pre-school education and was launched on $1^{\text {st }}$ September 2004 under royal patronage. All public kindergartens were provided with the new curriculum and the curriculum was put in empirical application at the beginning of the first semester for the academic year 2003/2004.

Creativity topic, factors that influence it, and ways to develop it are generally regarded among topics that attracted the attention of writers and researchers in the educational field. So there were many studies that were conducted to address creativity from various aspects. The authors of the current study noted the scarce research and studies that directly conducted on kindergartens, and many studies didn't focus on the role of school curriculum on the creative thinking development among children which led the researchers to conduct this research.

\section{Problem Statement}

Based on what the researchers know about kindergartens in Jordan, and based on the pilot study they conducted to investigate the creative thinking level, and self-efficacy among kindergartners, as six kindergartens were visited (three of which apply the interactive curriculum and three apply the private one) to determine the differences among children regarding the creative thinking and self-efficacy, the researchers noticed a virtual difference between the children in creative thinking skills and self-efficacy based on the curriculum 
applied and the gender of the child, hence, the researchers decided to conduct the study to ensure that these differences are statistically significant among children.

\section{Objectives}

The current study aims to identify the efficiency of the national interactive curriculum applied on kindergartens in the public sector and to compare it with the curriculums applied in the private sector in improving creative thinking skills and self efficacy among these children. In addition, the study seeks to identify the nature of the difference among children in creative thinking and self-efficacy based on gender.

\section{Research Questions}

1. Are there significant statistical differences in kindergartners' responses on creative thinking and self-efficacy that are attributed to the institution's type (private or public)?

2. Does the creative thinking and self-efficacy level differ based on gender (male/female)?

\section{Significance of the Study}

Creativity is regarded as an upscale phenomenon for human activity and its effects are reflected on any who possess it and who surrounding him/her in a fashion that generates new things from old things and these new things are characterized by fluency, flexibility, and authenticity (Mansi, 1993). Students can't achieve success in their school and social life when they possess a low creativity level. The significance of the current research emerges from that it enriches the psychological guidance with the nature of children adjustment and their creativity, and self-efficacy, and determining wither school curriculums contribute in improving creativity level among children, the extent to which children are differ regarding creative thinking skills, and self-efficacy among them based on gender. The results of the current research can be utilized and being placed at practical application within the educational institutions to ensure the importance of the interactive curriculum compared to other curriculums, and also to help curriculum developers to pay attention to the creative aspects among children since basic stages at school which in turn contributes later in increasing their creative level, in addition to help teachers who teach children to concern about the psychological and guidance aspects and in particular those related to self-efficacy since the first basic stages so as to develop the child in these important aspects as these aspects have a great effect on their life and motivation later.

\section{Concepts of the Study}

Kindergarten: Al-Hariri defined kindergarten as an educational and social institution that qualifies the child a healthy qualification to inter the elementary stage so as not to feel the sudden shift from home to school leaving the child with the whole freedom to practice his/her 
activities and to discover his/her abilities, attitudes and potentials. That is, it assists the child to acquire new experiences, and the age range of children at this stage is between 3-6 years.

The Interactive National Curriculum: one of the preschool learning development project achievements, this curriculum was developed by a national team specialized at early childhood and was supervised by the national committee for preschool education development. And this curriculum was approved by the educational council (Imad Addin, 2005).

Procedural Definition for The Interactive National Curriculum: one of the curriculums prepared by the ministry of education in Jordan for kindergartens and was put in empirical application since the beginning of the second semester for the academic year 2013/2014.

Creative Thinking Skills: Kamil (1996) defines creative thinking as the method that individual uses to produce the greatest number of thoughts and ideas in face of a problem (intellectual fluency) and these thoughts or ideas are characterized by variance and diversity (flexibility) and as being infrequent or common (authenticity). And procedurally, it is the score achieved by the kindergartner on Torrance test (the verbal aspect) that can be applied from the age of kindergarten to the age of higher studies with zero as its minimum score with no maximum limit.

Self-Efficacy: social learning theories define self-efficacy as the individual's feeling with confidence toward his/her specific achievements and skills. Bandura (1986) sees that through self-efficacy, individual can judge his/her ability to regulate and implement actions related to his/her achievements, he also stated that self-efficacy is concerned about individual's ability to judge what enable him/her to capture these skills and utilize them in real life. Procedurally, self-efficacy is defined as the score achieved by the child at kindergarten stage on the Arabic version of the scale designed for this purpose on which the score ranges from 30 to 120 as the score 30 represents the lowest level the child achieved on self-efficacy while the highest score indicates a high self-efficacy level.

\section{Methodology}

To achieve the goals of the study, the researchers followed the quasi-empirical approach based on the nature of the study.

\subsection{Population of the Study}

Population of the study included all kindergartners in Jordanian public and private schools at Southern Mazar educational district.

\subsection{Sample of the Study}

The sample of the study was consisted of (93) children whom were randomly selected (52 children from public schools and 41 children from private schools).

\subsection{Instrumentation}

To assess the effectiveness of the interactive comprehensive curriculum, the following 
instrument were either selected or developed for the purposes of the current study :

\subsubsection{First: Torrance tests for Creative Thinking}

One of the creative thinking skills tests which developed by Torrance (1966) and is used in the current study to assess to which extent is the advancement of creative thinking skills among the participants in the study. Torrance creative thinking tests in their American version have various validity indicators such as: content validity, validity of the scale construct, sincerity validity, and predictive validity. They are also have a high degree of validity (Al-Rousan, 1996).

During administration, the researchers utilized the verbal version of Torrance tests as most previous studies have utilized this version in addition to the difficulty faced in scoring the performance version. The test is consisted of three dimensions : fluency, flexibility, and authenticity with a different scoring method for each dimension as the sub-score for fluency is calculated by the total of the tested responses on the single test with one score on each single response. For flexibility, the sub-score is calculated by the total of responses categories that the tested responses on the single test as one score is given for each single category of responses. Finally, the authenticity sub-score which is calculated by the total authenticity scores achieved by the tested on each response as each response is given a score from 0 to $3(0,1,2,3)$.

\subsubsection{Second Self-Efficacy Scale}

Due to the scarce literature on self-efficacy, the researchers have developed an Arabic version of Jinks and Morgan's Self-Efficacy scale (1999) in their study on "Children's Perceived Self-Efficacy: Inventory Scale ", in its original version, the scale is consisted of 34 items.

\section{Validity and Reliability of the Scale in its Current Version:}

\section{First: Validity of the Scale:}

Coefficients of scale validity were calculated through the following methods, logical validity (arbitrators): logical validity was obtained by subscribing the scale on a jury of ten specialized arbitrators in education and psychology in Jordanian universities, and based on their views, two items were refined regarding formulation to increase their clarity, in addition to excluding four items.

Discriminate validity was also used through comparing performance within two different groups regarding characteristics for which the scale was constructed. Students who possessed academic self-efficacy were classified based on their academic achievement whom were accounted for (23) kindergartners and were compared to a group of (23) low achievers kindergartners. After application, the two groups performance was compared using (t-test), and it was shown that the scale was able to discriminate between them as t value was (6.7) which indicates a statistical value at the level $\alpha=0.05$, and mean of high achiever group was (4.3) while mean of low achiever group was (2.5) which indicates the scale ability to discriminate between both groups and the scale possesses discriminate validity.

Validity coefficients of the scale were also obtained by utilizing two methods: validity by 
replication, and internal validity, as the scale was applied on a pilot sample of (23) participants and then was applied again on the same sample two weeks later. Consistency coefficient was (0.72) and this value is acceptable for the purpose of this study. The scale was also applied on other pilot sample of (20) participants, then all questionnaires were analyzed using Kronbach alpha to calculate internal validity coefficients, and the total score was (0.78) and indicates an appropriate level of internal validity.

In its final version, the scale consisted of (30) positive items that assess one dimension, and participant had to select one of four multiple choices to response.

For the purposes of this study, the total score of the scale was calculated and ranged from 30 to 120 , and student whose total score approaches the maximum score (120) is classified as having a higher level of self-efficacy, and whose total score approaches (30) is classified as having low self-efficacy level.

\subsection{Date Collection and Analysis Procedures}

To achieve the goals of the study represented by identifying the effectiveness of kindergarten curriculum applied within kindergartens in developing creative thinking skills and self-efficacy among kindergarteners. The study was conducted as a pre application and then kindergartners were followed up to the end of the academic year as follows:

1- At the first semester of the academic year 2013/2014, 20 public and private kindergartens were visited, (7 private and 13 public kindergartens) in Al-Karak governorate. Torrance test for creative thinking and self-efficacy was applied on kindergarteners within these kindergartens. Female kindergartens teachers within the visited schools were asked to help in the study and the application of Torrance test. The study was applied on a sample of (136) male and female kindergartners after excluding the wrong items. Students' names were recorded on the copy of the scale in addition to information regarding their gender.

2-The researchers ensured equivalence of the two groups which included (93) participants from public and private schools regarding self-efficacy and creative thinking, and to check for wither the differences were major ones and statistically significant, t-test of independent samples was utilized as shown in table (1).

Table 1. T-Test Independent Results for Differences among the Two Groups in Public and Private Kindergartens Regarding self-Efficacy and Creative Thin King

\begin{tabular}{llllllll}
\hline Dimension & Group & $\begin{array}{l}\text { Students } \\
\text { No }\end{array}$ & Mean & SD & $\begin{array}{l}\text { Freedom } \\
\text { scores }\end{array}$ & $\begin{array}{l}\text { T } \\
\text { value }\end{array}$ & Significance \\
\hline $\begin{array}{l}\text { Creative } \\
\text { Thinking }\end{array}$ & $\begin{array}{l}\text { Private } \\
\text { schools }\end{array}$ & 60 & 5.93 & 2.51 & 101 & 0.05 & \\
& $\begin{array}{l}\text { Public } \\
\text { schools }\end{array}$ & 43 & 5.90 & 2.71 & & & 0.96 \\
Self-Efficacy & $\begin{array}{l}\text { Private } \\
\text { schools }\end{array}$ & 60 & 1.67 & 3.5 & 101 & 0.74 & \\
& $\begin{array}{l}\text { Public } \\
\text { schools }\end{array}$ & 43 & 1.61 & 3.5 & & & 0.55 \\
\hline
\end{tabular}


Data shown in table (1) indicate simple apparent differences in means between public and private kindergartners in creative thinking and self-efficacy, and when t calculated values and the associated significance level were reviewed, it is clear that there are no significant statistical differences at the value $(\alpha \geq 0.05)$ in creative thinking and self-efficacy levels which indicates that both groups are equivalent.

3- At the end of the second semester, the same kindergartens were revisited and the researchers managed to apply the study only on (95) of the original sample and Torrance test for creative thinking and self-efficacy was again applied on them.

4- After collecting data about the participants, two questionnaires were excluded due to the inappropriate response and the lack for information, hence the questionnaires of (93) participants were analyzed which means that the final sample was (93) kindergartners in the second application.

5- Questionnaires were collected and data were computed for analysis.

\section{Results}

Results of the first research question: Are there significant statistical differences in kindergartners' responses on creative thinking and self-efficacy that are attributed to the institution's type (private or public)?

To answer this question, t-test was used to identify the differences in kindergartners' responses based on institution's type (private/public) as shown in table (2).

Table 2. T-Test Results for Kindergartners' Responses on Creative Thinking and Self-Efficacy Based on the Type of Institution (private/public)

\begin{tabular}{lllllll}
\hline $\begin{array}{l}\text { School } \\
\text { Type }\end{array}$ & Variable & Mean & SD & $\begin{array}{l}\text { Freedom } \\
\text { Score }\end{array}$ & T value & $\begin{array}{l}\text { Significance } \\
\text { level }\end{array}$ \\
\hline Private & Self-Efficacy & 1.73 & 0,35 & -0.74 & 91 & 0.63 \\
& $\begin{array}{l}\text { Creative } \\
\text { Thinking }\end{array}$ & 5.52 & 2.76 & & & \\
Public & Self-Efficacy & 1.67 & 0.32 & -0.79 & 91 & 0.43 \\
& $\begin{array}{l}\text { Creative } \\
\text { Thinking }\end{array}$ & 5.95 & 2.66 & & & \\
& & & & & \\
\hline
\end{tabular}

Results of the second research question: Does the creative thinking and self-efficacy level differ based on gender (male/female)?

To answer this question, t-test independent was used as shown in table (3). 
Table 3. T-Test Independent Results Based on Gender (male/female)

\begin{tabular}{lllllll}
\hline Variable & Gender & Mean & SD & $\begin{array}{l}\text { Freedom } \\
\text { Score }\end{array}$ & T value & $\begin{array}{l}\text { Significance } \\
\text { Level }\end{array}$ \\
\hline Self-Efficacy & Males & 1.76 & 0.40 & 91 & 0.75 & 0.45 \\
& Females & 1.71 & 0.23 & & & \\
Creative & Males & 5.14 & 2.68 & 91 & -27.2 & 0.03 \\
Thinking & Females & 6.37 & 2.50 & & & \\
\hline
\end{tabular}

\section{Findings and Discussion}

\subsection{Findings}

1. students' responses on creative thinking and self-efficacy scale, means of students' responses were the close to each other at most with little differences, but the difference was statistically significant at the level $(\alpha \geq 0.05)$ between students' responses on the scale and on Torrance test based on the institution's type variable (private/public), and it is worth to mention that - based on the researchers best knowledge - there are no direct studies to link this result with regarding agreement or not, as there was no study have been conducted on the same topic of the current study to compare between curriculums applied within Jordanian public and private kindergartens, and all previous studies included the effectiveness of already used programs on these kindergartners to develop creative thinking, these studies indicated the effectiveness of these programs such as Al-A'lawnah's study (1998), Olenchak (1995), and Gomes' study (2005).

2. it can be inferred that there are no significant statistical differences between males and females in self-efficacy, while there were significant statistical differences between male and female kindergartners regarding creative thinking in favor of female kindergartners as mean of females' responses was (6.37) while was for males' responses (5.14). This result is in agreement with what Al-Habeeb (1991) indicated in his study that there were no significant statistical differences between males and females in creative thinking, while isn't in agreement with the results of Al-Hadhli (2005) and Al-A'losi (1981) which indicated significant statistical differences between males and females, and it is worth to mention that these two studies utilized training programs for developing creative thinking and didn't utilize schools curriculum as a criterion of judgment

\subsection{Discussion}

1. The reason of this result (there are no significant statistical differences between interactive curriculum and ordinary curriculum) would be attributed to both public and private schools' concerns about developing creative thinking skills by offering effective activities and experiences for students represented by the qualified teaching stuff, and this result would be also attributed to parents' concerns about this age category, as parents pay a great and special attention to their children at this stage, in addition to the specialization of public schools' principals in distinguished programs that contribute in paying attention to students and 
improving their abilities and life skills.

2. The absence of differences in this study is attributed to the level of effort exerted by female teachers with both male and female kindergartners as they are exposed to the same achievement tests and the same curriculum and receive the same skills. For creative thinking and females' superiority over males, this would be attributed - from the researchers' perspective- to that female kindergartners at this age possess higher level of linguistic fluency than males at the same age, as females precede males in linguistic fluency and hence in creativity, but both would be equivalent in later stages.

3. In light of the results revealed by this study, the researchers concluded with a group of various recommendations, among which: the necessity of concerning about developing creative thinking and self-efficacy among kindergartners through what is offered to them of curriculums, stories, and various tools of communication, and not to separate activities that work on developing creative abilities from other educational activities offered to kindergartners. Increasing attention of kindergartens' curriculum developers and the necessity of including activities that promote creative thinking, in addition, attention must be paid for females' superiority over males regarding creative thinking and assigning some appropriate activities for developing males. Finally, there is a need for conducting training courses and workshops for kindergartens' female teachers regarding how to develop creative thinking skills.

\section{Recommendations}

Based on the result of the current study the researchers recommended the following:

1. Training of kindergarten teachers on methods of teaching to serve the creative and move away from too much emphasis only literacy and writings skills only.

2. Increased focus by the supervisors performance on the kindergarten methods and provide them with modern methods and appropriate activities that develop the skill of creative thinking.

\section{Contributions of the Study to Knowledge}

Improved and development of counseling programs for kindergarten, also helps in the development of creative thinking had, and Self-Efficacy among Kindergartners.

\section{Limitations of the Study}

The study determined in kindergarten from the age of 5-6 years, as determined in Karak governorate, and in the academic year 2014-2015, as determined in the study used tools: creative thinking scale, and scale self-efficacy. 


\section{Areas for Further Research}

1. conduct a similar study on the different age stages

2. Development of self-efficacy in children at the age of 5-6 years through training programs and counseling.

3. the impact of creative thinking in the psychological adjustment

4. The relationship between self-efficacy and family upbringing of the child at the age of 5-6 years

\section{References}

Al-A'lawneh, Shafiq Falah. (1996). Developing Innovation and Innovative Care in Elementary Schools in Bahrain. Journal of Psychological Sciences, 4, 100-120.

Al-A'losi, Sa'ib Ahmad. (1981). The Effect of Using Some Educational Activities and Methods on Teaching the Development of Creative Thinking Abilities Among Elementary School Students. Unpublished PhD Thesis. Baghdad University, Bghdad.

Al-A'nani, Hanan (2002). Child's Cognitive and Linguistic Development (1 ${ }^{\text {st }}$ Ed.). Dar Al-Fikr for Publication, Amman/Jordan.

Al-A'ni, Ra'ouf Abderrazzaq (1987). New Attitudes in Teaching Science. Ryadh, Dar Al-O'loum.

Al-A'ssaf, Jamal, Latifah \& Ra'ed. (2008). Kindergarten Curriculum (cnotemorary Vision). $1^{\text {st }}$ Ed, Arab Society Library for Publication. Amman /Jordan.

Al-Hariri, Rafidah. (2002). Emergence and Management of Kindergartens from Islamic and scientific Perspective. Riyadh, Saudi Arabia, Al-Obiekan Library.,

Al-Hdhili, Nihad Salih (2005). Effectiveness of Playing-Based Training Program in Development of Creative Thinking among Hearing Disable Children of Pre School Stage in A Jordanian Sample. Unpublished PhD Thesis, The University of Jordan. Amman, Jordan.

Al-Rosan, Farouq. (1996). Measurement Methods in Special Education. Amman, Dar Al-Fikr for Publication: Jordan.

Assrour, Nadia. (2005). Teaching Thinking through School Curriculum. Amman/Jordan, Dar Wa'el for Publication.

Badran, Adnan. (2000). Human Capital and Management in Quality: Strategies for Globalization Era in Teaching and Arab World. Abu Babhi, Emirates Center of Strategic Studies and Research.

Bandura, A. (1991a). Self-efficacy mechanism in physiological activation and health-promoting behavior. In J. Madden, IV (Ed.), Neurobiology of learning, emotion and affect (pp. 229- 270). New York: Raven 
Bandura, Albert. (1986). Social foundations of thought and action: A social cognitive theory. Prentice-Hall (Englewood Cliffs, N.J.)

Duffy, B. (1998). Supporting Creativityand Imagination in the Early Years. Biddles ltd., Britain.

Emad Addin, Muna Mu'taman. (2005). The Interactive National Curriculum Applied in Jordanian Public Kindergartens. Ministry of Education, Jordan.

Gomes, J.M. (2005). Using a creativity- Focused Science to Foster General Creativity in Young Children: A Teaches Action Research Study Ed. D., Fielding Graduate. DistAbst. (Proquest. Dissertation and Theses) 15/7/1430.

Habeeb, Abdelkareem. (1991). Functioning Interaction of Self-Concept, Self-Esteem, and Creative Thinking Among A Sample of $4^{\text {th }}, 5^{\text {th }}$ and $7^{\text {th }}$ Graders (Published Research). The 4th Annual Conference for Egyptian Child, childhood Higher Studies Center. $1^{\text {st }}$ issue, Ain Shams University.

Jinks, J., \& Morgan, V. (1999). Morgan-Jinks Student Efficacy Scale (MJSES) Children's perceived academic self-efficacy: An inventory scale. The Clearing House, 72(4), 224-230. http://dx.doi.org/10.1080/00098659909599398

Kamil, Michael Muneer. (1996). Scientific Education Seminar and Development Requirments in the $21^{\text {st }}$ Century. Science Development Center, Ain Shams University, p4-5.

Mansi, Mahloud Abdelhaleem. (1993). Basic Education and Students' Creativity. Education and Creativity Series, (2). Alexandria, Dar AL-Ma'rifah. Egypt.

Murdan, Najm Addin. (2004). The Educational Reference for Kindergartens' Programs. Al-Falah Library, Amman/ Jordan.

Olenchak, F. (1995). Effects of enrichments on gifted/learning- disabled students. Journal of the Education of the gifted, 18(4), 385-399. http://dx.doi.org/10.1177/016235329501800403

Schwarzer, R. (1994). Optimistische Kompetenzerwartung: zur Erfassung einer personellen Bewaeltigungsressource. Dignostika, Heft, 2(40), 105-123

\section{Copyright Disclaimer}

Copyright for this article is retained by the author(s), with first publication rights granted to the journal.

This is an open-access article distributed under the terms and conditions of the Creative Commons Attribution license (http://creativecommons.org/licenses/by/3.0/). 